\title{
CONEXÃO ENTRE MICRO E PEQUENAS EMPRESAS E DESIGNERS VIA PLATAFORMAS \\ DE DESIGN
}

\section{CONNECTION BETWEEN MICRO AND SMALL COMPANIES AND DESIGNERS VIA DESIGN PLATFORMS}

Gilvani Schmidt Hoffmann Norenberg ${ }^{1}$ Carlo Franzato ${ }^{2}$ 


\section{Resumo}

O presente artigo tem como objetivo analisar o desenvolvimento e o funcionamento de plataformas de design para a interação entre MPE's e designers, entendidas como instrumento estratégico para a inserção do design nestas realidades organizacionais. A partir de um referencial teórico sobre redes de cooperação, design estratégico e plataformas de design, foi desenvolvido um estudo de casos múltiplos de natureza exploratória sobre esse assunto. Os casos estudados são Projeto Maestro e Invalley Inovação e Design1, que permitem explorar aspectos diferentes das plataformas de design. Dessa forma, este estudo investigou a realidade atual de uma nova modalidade de negócio e contextualizou a importância das plataformas de design para alavancar desenvolvimento e pequenas inovações e, como resultados obtidos destacam-se: (re)conceituação de plataformas de design, um novo mercado para prestação de serviços de design, as consequências do design e a importância da relação no processo projetual.

Palavras-Chave: Plataformas de Design. Design Estratégico. Inovação. Micro e Pequenas Empresas (MPE's).

Conforme documento de autorização de uso de imagem

${ }^{1}$ Gilvani Schmidt Hoffmann Norenberg Sociedade Educacional Três de Maio gilvaninorenberg@gmail.com

\section{Abstract}

This paper aims to analyze the development and design of operating platforms for interaction between MSE and designers, understood as a strategic tool for the design of the insertion in these organizational realities. From a theoretical framework on cooperation networks, strategic design and design platforms, a multiple case study of exploratory nature on this subject was developed. The case studies are Maestro Project and Invalley Innovation and Design, exploiting different aspects of design platforms. Thus, this study investigated the current reality of a new type of business and contextualized the importance of design platforms to leverage development and small innovations and, as the results obtained are: (re) conceptualization of design platforms, a new market to provide design services, design the consequences and the importance of the relationship in the design process.

Keywords: Design Platform. Strategic Design. Innovation. Micro and Small Enterprises (MSEs).

ISSN: 1808-3129
${ }^{2}$ Carlo Franzato
Universidade do Vale do Rio dos Sinos
carlo.franzato@gmail.com 


\section{INTRODUÇÃO}

O ritmo acelerado da concorrência imposta pela globalização que envolve o mercado brasileiro pressiona, principalmente, as Micro e Pequenas Empresas (MPE's) com oferta de produtos com elevado nível de desenvolvimento industrial e custos mais baixos. Portanto, a atualidade exige uma nova postura das empresas obrigando -as a buscar novos conhecimentos e a renovar suas práticas estratégicas.

O crescente interesse pelo desenvolvimento das MPE's vem motivando muitas pesquisas. Alguns estudos enfatizam que os esforços de aprendizagem e inovação estão deslocando-se de um processo individual para um processo coletivo em rede (BALESTRIN; VERSCHOORE, 2008). Tal atitude abre novos espaços para MPE's que souberem inserir-se nos muitos nichos de mercado. Portanto, o estudo de plataformas de design como instrumento estratégico para alavancar mudanças em MPE's torna-se fundamental.

Diante disso, justifica-se, neste estudo, a abordagem de redes de cooperação por meio de plataformas de design para inserir o design e pequenas inovações em MPE's, pois, é notável a importância do design e da necessidade de fomentar debates acerca das possibilidades de alavancar mudanças para as MPE's, em que são enfatizadas as estratégias interorganizacionais das plataformas pesquisadas.

Para reforçar a importância das interações projetuais e de relações entre organizações para o desenvolvimento e inovação de MPE's, o estudo apresentado por Balestrin e Verschoore (2008) ressalta que, independente da configuração da rede, as redes de cooperação indicam um caminho alternativo para fazer frente às pressões competitivas. Contudo, as dinâmicas de interação e as formas de interação podem contribuir para o desenvolvimento dessas MPE's e que as formas de relação estão conectadas à cooperação, mas também estão conectadas a outro tipo de relações, como, por exemplo, as relações competitivas.

Considerando o advento das novas tecnologias, a questão que se destaca para o presente estudo é: como as novas tecnologias podem ajudar nessa conexão entre designers e MPE's. As plataformas de design parecem uma alternativa interessante, pois permitem a relação e a interação entre pessoas distintas e evitam problemas temporais, geográficos e de relacionamento existentes na forma de conexão tradicional.

Com a finalidade de destacar a importância das plataformas de design, o presente artigo tem por objetivo analisar o desenvolvimento e o funcionamento de plataformas de design para a conexão entre MPE's e designers. Além de descrever o estado da arte dessa nova modalidade de negócio para o design, o estudo foca especialmente nas abordagens processuais praticadas nessas plataformas e nas dinâmicas de relação e interação entre os atores que se relacionam por meio delas que são os articuladores, os designers e os empresários. Os casos estudados são: Projeto Maestro, que oferece design de comunicação para clientes que não tinham acesso a design de comunicação em função do preço e da região geográfica de localização e a Invalley Inovação e Design, que transforma conhecimentos de diversos setores em soluções rentáveis, com a finalidade de ajudar as empresas a gerarem competitivida- 
de e valor através do design e projetos inovadores.

Perante esse desafio, as plataformas de design se apresentam como um instrumento estratégico para fomentar o design em MPE's. De acordo com Arquilla e Genco (2008) entendem-se as plataformas de design como pontos de encontro virtuais para a troca de conhecimentos e desenvolvimento de projetos inovadores entre empresários, designers e outros profissionais. Explorando o potencial das novas tecnologias, as plataformas de design permitem relações e interações entre esses atores sem limites geográficos ou temporais.

Por meio das plataformas de design, empresas situadas em áreas remotas podem entrar em contato com designers que atuam nos principais polos urbanos da indústria criativa. Logo, as plataformas de design podem ser consideradas instrumentos estratégicos para apoiar rapidamente o desenvolvimento de produtos, processos ou serviços de forma integrada. As plataformas de design parecem uma solução ainda nova e pouco explorada; portanto, uma maior compreensão do seu desenvolvimento e do seu funcionamento é importante em termos teóricos e para socialização desse instrumento. 


\section{REDES DE COOPERAÇÃO}

No atual cenário econômico, de mudanças tecnológicas e de alta competitividade, faz-se necessário que as empresas, principalmente MPE's, repensem seus espaços e busquem novas formas de disputar o mercado, sob pena de não sobreviverem à concorrência das grandes organizações. Nesse sentido, surgem as redes de cooperação ou redes de empresas com interesses e objetivos comuns.

$\mathrm{Na}$ visão de Balestrin e Verschoore (2008), as redes de cooperação indicam um caminho alternativo para fazer frente às pressões competitivas, em que a interação entre os envolvidos representa mais do que uma simples adaptação passiva, pois os relacionamentos enfrentam dificuldades comuns e buscam por soluções conjuntas por meio das diversas capacitações reunidas e daquelas originadas pela sinergia coletiva.

Amato Neto (2000) conceitua redes de empresas como um tipo de agrupamento de empresas, cujo objetivo principal é o de fortalecer as atividades de cada um dos participantes da rede sem que, necessariamente, tenham laços financeiros entre si. Mas, atuando em redes, as empresas podem complementar umas às outras, tanto nos aspectos técnicos (meios produtivos), como mercadológicos. Enfim, a constituição de uma rede pode ter vários objetivos, já que se trata de um modo de associação por afinidade.

De modo geral, o objetivo das redes é promover a cooperação entre as empresas parceiras. Isso lhes permite a realização de ações conjuntas, facilitando a solução de problemas comuns e a visualização de novas oportunidades.

Através da formação de redes de cooperação, identificam-se evidências delas servirem como recursos estratégicos para melhorar o desempenho competitivo das MPE's, salientam Balestrin e Vargas (2004). Pois, para poder competir num ambiente globalizado, as MPE's terão que se adaptar aos novos padrões de qualidade e também melhorar as formas de integração e cooperação com agentes envolvidos.

Dessa forma, as relações entre empresas têm sido tema de estudos de vários pesquisadores, pois, para melhor compreender o desempenho competitivo das empresas, é necessário entender as relações entre as empresas e as demais instituições dentro de um espaço geográfico definido.

Com ganhos positivos provenientes da otimização de recursos, aumento da capacidade de produção, acesso à tecnologia, melhoria da capacidade de inovação, obtenção de crédito e penetração em novos mercados, as estruturas produtivas organizadas em redes de cooperação passam a obter vantagens competitivas significativas na disputa por mercados nacionais ou mundiais.

\section{DESIGN ESTRATÉGICO}

Segundo Meroni (2008) e Zurlo (2010), o design estratégico e seus métodos surgem para permitir que o design concorra ao desenvolvimento das estratégias 
empresariais frente à complexidade do cenário contemporâneo, caracterizado pela abertura dos sistemas de produção e consumo, e consequentemente, por um número crescente de relações e interações turbulentas entre organizações que atuam na escala global e em tempo real. Nesse cenário, as habilidades projetuais se tornam importantes para delinear caminhos de desenvolvimento estratégico e para praticá-los.

Nesse sentido, o design estratégico é especialmente útil para o desenvolvimento de estratégias interorganizacionais que explorem tais relações e interações, e sua prática pode ser eficaz para alavancar mudança nos polos de micro e pequenas empresas.

Com o crescimento dos mercados, em qualquer parte do mundo, proporcionado pela globalização da economia e dos avanços tecnológicos, abre novos espaços para MPE's que souberem se inserir, de forma inteligente e maleável, nos muitos nichos abertos ao desenvolvimento.

Teixeira (2005) destaca que, ao antecipar possíveis cenários de atuação competitiva das empresas, o design estratégico atua como um componente fundamental para o incremento da competitividade empresarial.

Silva (2004) individualiza seis modalidades que o design pode proporcionar às MPE's para aumentar sua competitividade: a) como fator de fortalecimento da inserção competitiva nos mercados locais, nacionais e internacionais; b) enquanto instrumento de aumento de conhecimentos e valor adicionados aos bens e serviços produzidos por MPE's; c) enquanto instrumento que contribui para a melhoria da imagem e da competitividade de bens e serviços produzidos, assim como das empresas, regiões e países; d) como processo que abrange conhecimentos dentro de perspectiva integrada e sistêmica; e) enquanto atividade que, através de possibilidades técnicas e oportunidades de mercado, mobiliza tanto inovações tecnológicas quanto organizacionais; f) como elemento estratégico na promoção da articulação entre diferentes empresas e outros agentes econômicos relevantes em sistemas produtivos locais.

Lastres e Pimentel (2001) distinguem alguns fatores básicos em que o design, através do método do design estratégico, pode ser incorporado no contexto de gestão das MPE's: a) nos projetos enquanto método e processo de desenvolvimento de novos produtos; b) nas políticas que orientam os recursos e critérios de design que facilitam a tomada de decisão e procuram estabelecer as bases sobre como os objetivos e desafios serão alcançados; c) nas estratégias que estabelecem ações que alcancem os objetivos da empresa e ajudem a superar desafios que levem à liderança de mercado, seja por meio da racionalização ou da diferenciação.

A integração do design nos processos das MPE's deve ser viabilizada com cuidado para resultar economicamente sustentável. Berends (2011) sugere que as MPE's colaborem com designers externos, que possam atenuar a falta de habilidades e criar soluções para projetos de design. Uma vez que os recursos das MPE's são limitados, a despesa com design pode ser controlada com a colaboração de designer externo. Assim, através da experimentação de designers externos, as MPE's podem reconhecer o valor do design e se beneficiar dele.

Berends (2011) reconhece a vantagem da colaboração entre MPE's e designers externos, mas afirma que esta possibilidade não é muito praticada pelas empresas. 
Um dos fatores é certamente a distância geográfica e até cultural que divide as MPE's dos designers. As MPE's, de fato, podem ser situadas longe das cidades em que se concentram os profissionais. As plataformas de design podem permitir sua aproximação.

\section{PLATAFORMAS DE DESIGN}

Nos últimos anos, ocorreram grandes avanços econômicos e tecnológicos. Para acompanhar essa evolução, os recursos também proporcionaram avanços. Na visão de Figueirôa (2007), essa responsabilidade de aperfeiçoar o processo industrial recai sobre os designers.

Nessa circunstância é que surgem as plataformas cujo conceito não é claro e nem definido, mas algumas definições teóricas começam a surgir. Para Braga (2012), o termo plataforma representa um pacote de ferramentas agrupadas a qual apresenta diversas características (funcionalidades) em uma só aplicação.

Na visão de Altizer (2002), uma plataforma é um ambiente de interação e reutilização projetado, especificamente, para atingir um domínio de aplicação. De fato, as plataformas permitem arranjos através de organizações virtuais e essas organizações virtuais são uma forma de cooperação entre empresas ou organizações, constituindo dinâmicas de cooperação que, por meio das tecnologias da informação, apresentam alguns objetivos: viabilizar o acesso a novos mercados, sem os tradicionais limites de espaço e tempo; elevar o poder de competitividade dos parceiros componentes dessa rede virtual e possibilitar a inovação e a exploração de novas oportunidades de mercado em nível global.

Considera-se que o desenvolvimento de plataformas de design ainda se encontra num estágio embrionário e a interação, além das fronteiras físicas, incorpora uma nova dimensão do design, capaz de gerar dinâmicas importantes de socialização e aprendizagem. No entanto, a plataforma pode ser um conjunto de ativos usados para alcançar e prosperar negócios, definir ambientes operacionais e desenvolver produtos para MPE's.

Arquilla e Genco (2008) enfatiza que é necessário criar ambientes em que designers podem compartilhar conhecimentos de forma mais intensa, criar iniciativas para o aprofundamento e enriquecimento de conhecimentos que emergem a partir das demandas do mercado. Tal atitude é necessária para desencadear um processo de inovação em MPE's, pois a criatividade dos designers deve ser integrada e desenvolvida a partir de habilidades cognitivas e podem fornecer estímulos, ideias e pontos de vista diferentes.

As plataformas de design apresentam características benéficas para os designers e empresários, permite a compreensão da forma e da estrutura de objetos e lugares. A plataforma pode ser usada como ambiente de simulação; pode ser usada para visualizar processos, operações e atividades em tempo real, bem como proporcionar a avaliação de protótipos e levando em consideração a interatividade, os usuários podem interagir com os artefatos simulados e experimentar uma forma simplificada. 
Além disso, a capacidade de adicionar, excluir e manipular objetos em tempo real permite que vários usuários construam uma solução de forma sincronizada e consciente de outras ações a cada instante.

Os ambientes virtuais podem ser usados como uma plataforma poderosa para a concepção de novos ambientes de design colaborativo (MERRICK et al, 2011). Através das plataformas de design, os integrantes interagem compartilhando ideias, soluções para problemas, experiências técnicas e conhecimento tácito, favorecendo a aprendizagem nas organizações.

Uma das características essenciais de uma plataforma é o conhecimento integrado. Esse deverá ser maior do que a soma do conhecimento individual dos seus participantes. Portanto, destaca-se a importância de se desenvolver a confiança entre os atores da plataforma de design para que ocorra a colaboração, a satisfação e a harmonia entre seus membros.

Os recursos proporcionados pela internet possibilitam a criação de plataformas de design, congregando membros de diferentes regiões e para diferentes finalidades. Nesse sentido, Goldman (1995) enfatiza alguns motivos que justificam a interação através de uma plataforma virtual: (1) a formação de uma organização virtual para comercializar um produto permite que a empresa compartilhe recursos de infraestrutura, P\&D, custos e riscos; (2) valorização de oportunidades para desenvolvimento de produto para a empresa, unindo as principais competências internas às principais competências de outras empresas; (3) redução de tempo através da integração de conhecimentos e habilidades, além dos limites da empresa em operações simultâneas; (4) acesso a novos mercados por meio da formação de parcerias e por meio do valor agregado ao produto desenvolvido em conjunto; (5) possibilidade de migração para novas modalidades de negócio, da venda de produto para a venda de soluções.

Segundo Arquilla e Genco (2008), o mundo do design em MPE's é aparentemente inconsciente e diferente, em que cada empresa contém um panorama de valores, sistemas de conhecimento, habilidades e capacidades. No entanto, ambos precisam se unir para dar forma aos caminhos do desenvolvimento. Nesse sentido, as plataformas de design têm a capacidade de conectar esses mundos distantes e formar uma cultura baseada em projeto para relacionar-se com design e fazer design.

A plataforma de design é uma forma através da qual uma organização de intermediação viabiliza essas colaborações. E quando o projeto deverá ser desenvolvido em equipes, o design colaborativo é certamente uma opção e a plataforma de design pode ser uma ferramenta de apoio extremamente funcional, para incentivar a colaboração, direta e indiretamente e a busca pela inovação.

O contexto de uma plataforma de design, porém, deixa várias dúvidas que ainda não são explicadas por pesquisadores: de que forma essa rede de colaboração viabiliza o trabalho remoto? Como é desenvolvido o trabalho de interação, de proximidade e troca de conhecimentos? Quem são os intermediários que oportunizam novos negócios? Como funciona essa intermediação, o domínio e a aplicabilidade do contexto? De que forma é desenvolvido o processo de inovação?

Diante desse contexto, alguns critérios foram elaborados para serem analisados de acordo com conceitos chaves extraídos do aporte teórico, conforme ilustra o 
quadro abaixo, a qual expõe, também, a descrição dos critérios que serão analisados no decorrer da análise de dados das duas plataformas de design.

\begin{tabular}{|c|c|c|}
\hline Critérios & Descrição & Fonte \\
\hline Negócio e Oferta & $\begin{array}{l}\text { Em uma plataforma de design é possível personalizar e programar sua } \\
\text { aplicabilidade, de acordo com o modelo de negócio que a plataforma } \\
\text { oferece. } \\
\text { - Projetos } \\
\text { - Produtos } \\
\text { - Serviços } \\
\text { - Distribuicão }\end{array}$ & $\begin{array}{l}\text { Altizer (2002) } \\
\text { Sangiovanni (2002) }\end{array}$ \\
\hline Domínio & $\begin{array}{l}\text { A caracterização de uma plataforma depende do domínio e abrangência } \\
\text { de seu trabalho para com os atores envolvidos. No entanto, o domínio } \\
\text { é selecionado com base em objetivos de mercado. } \\
\text { Desse modo, as plataformas podem abranger uma área: } \\
\text { - Local } \\
\text { - Regional } \\
\text { - Nacional } \\
\text { - Internacional }\end{array}$ & $\begin{array}{l}\text { Altizer (2002) } \\
\text { Sangiovanni (2002) }\end{array}$ \\
\hline Interação projetual & $\begin{array}{l}\text { Através da interação entre atores envolvidos nas plataformas de design, } \\
\text { enfrentam-se dificuldades comuns e buscam-se soluções conjuntas, por } \\
\text { meio da soma de capacitações e competências e daquelas originadas pela } \\
\text { sinergia coletiva. } \\
\text { Sendo assim, a interação entre atores caracteriza-se de suas formas } \\
\text { distintas: } \\
\text { - Interação divergente: diz respeito à exploração de várias direções de } \\
\text { desenvolvimento e a criação de novas ideias, estratégias e redes. } \\
\text { - Interação convergente: é o refinamento de ideias geradas na fase } \\
\text { divergente. }\end{array}$ & $\begin{array}{l}\text { Amato Neto (2000) } \\
\text { Altizer (2002) } \\
\text { Berends (2011) } \\
\text { Goldman (1995) }\end{array}$ \\
\hline Cooperação & $\begin{array}{l}\text { As redes de cooperação indicam um caminho alternativo para fazer } \\
\text { frente às pressões competitivas. } \\
\text { Para enfrentar esse critério será analisado: } \\
\text { - Relações internas } \\
\text { - Relações externas }\end{array}$ & $\begin{array}{l}\text { Amato Neto (2000) } \\
\text { Balestrin e Verschoore (2008) } \\
\text { Arquilla (2006) e (2008) } \\
\text { Berendes (2011) } \\
\text { Koutsabasis (2011) } \\
\text { Merrichk (2011) }\end{array}$ \\
\hline
\end{tabular}

Quadro 1 - Critérios de análise.

\section{PROCEDIMENTOS METODOLÓGICOS}

Este estudo possui uma natureza qualitativa com finalidades exploratórias. Através dessa abordagem pretende-se desenvolver conhecimento sobre o tema pesquisado, especificamente sobre a forma de organização, desenvolvimento e funcionamento das plataformas de design, assumindo uma postura interpretativa em relação às estratégias interorganizacionais.

Para a descoberta e compreensão do contexto de desenvolvimento e funcionamento de plataformas de design, foi realizado um estudo de caso e este auxiliará a expandir teorias recentes. Como as plataformas de design integram diversos atores - articuladores, designers e empresários - utilizou-se um estudo de casos múltiplos de unidade integrada de análise (YIN, 2010, p. 77).

Escolheu-se estudar as plataformas Projeto Maestro e a Invalley Inovação e Design. O Projeto Maestro realiza seu trabalho de forma remota interagindo com designers e empresários e oferece design de comunicação para clientes que não tinham acesso a design de comunicação em função do preço e da região geográfica de localização; dessa forma, o objetivo do projeto é servir como um intermediário entre designers e as MPE's. Já a Invalley Inovação e Design realiza seu trabalho de forma presencial interagindo com designers, empresários e investidores, potencializando oportunidades e inovações para os mais variados produtos e serviços, transforman- 
do conhecimentos de diversos setores em soluções rentáveis, com a finalidade de ajudar as empresas a gerarem competitividade e valor, através do design e projetos inovadores.

Para a efetivação desta pesquisa e o alcance dos objetivos propostos, utilizouse a entrevista de profundidade semiestruturada e a pesquisa documental como técnica para coleta de dados. Foram entrevistados o articulador da plataforma, um (1) designer e um (1) empresário de cada plataforma.

Para realizar a análise dos dados, aplicou-se a análise de conteúdo. Para proceder à análise, foram categorizados alguns critérios de acordo com conceitos-chaves extraídos do referencial teórico (quadro 1 - critérios de análise).

A partir desses critérios, buscaram-se as respostas nas entrevistas e na pesquisa documental. Os dados foram triangulados através do cruzamento de fontes distintas (articulador, designer e empresário).

\section{PROJETO MAESTRO E INVALLEY INOVAÇÃO E DESIGN}

Ao analisar detalhadamente as características de cada plataforma, observa-se que são projetos com objetivos diferentes; no entanto, não foram realizadas comparações entre as duas plataformas e sim uma investigação do contexto em que se inserem. Dessa forma, a pesquisa representa uma fonte de conhecimento dessa modalidade de negócio.

O quadro abaixo recolhe insumos sobre as plataformas estudadas, derivados das entrevistas e do material documental coletados, e subdivididos nos quatro critérios que orientaram a análise.

\begin{tabular}{|c|c|c|}
\hline Critérios de análise & Projeto Maestro & Invalley Inovação e Design \\
\hline Negócio e Oferta & $\begin{array}{l}\text { - Não tem estrutura física } \\
\text { - Oferecer o melhor custo beneficio de design de } \\
\text { comunicação para empresas de qualquer localidade, } \\
\text { com bons profissionais e qualidade. } \\
\text { - É apenas um projeto que articula com designers e } \\
\text { empresários. } \\
\text { - É uma rede aberta, de inovação aberta. } \\
\text { - Tem a identidade visual como o principal produto. }\end{array}$ & $\begin{array}{l}\text { - E uma empresa registrada com estrutura fisica, que dispõe } \\
\text { de um espaço fisico para desenvolver design colaborativo } \\
\text { através de uma multidisciplinaridade de profissionais. } \\
\text { - Tem foco no design thinking e no design centrado no } \\
\text { usuário. } \\
\text { - É orientada para pequenas e médias empresas. } \\
\text { - Trabalha o conceito de design e estratégias de design. } \\
\text { - Tem a consultoria como o principal produto. }\end{array}$ \\
\hline Domínio & $\begin{array}{l}\text { - A plataforma dispõe de relações locais, regionais, } \\
\text { estaduais e nacionais. }\end{array}$ & $\begin{array}{l}\text { - O trabalho realizado pela plataforma abrange domínio } \\
\text { local e regional. }\end{array}$ \\
\hline Interação projetual & $\begin{array}{l}\text { - Toda a interação é realizada via rede de internet. } \\
\text { - Não são realizados encontros presenciais }\end{array}$ & $\begin{array}{l}\text { - A interação para estruturação de projetos é realizada em } \\
\text { encontros presenciais. } \\
\text { - No processo de projeto não é utilizada a rede internet } \\
\text { como parte do processo. } \\
\text { - Os projetos são focados em consultoria e design e também } \\
\text { na aplicação da consultoria. }\end{array}$ \\
\hline Cooperação & $\begin{array}{l}\text { - Qualquer pessoa pode participar e contribuir com os } \\
\text { projetos. } \\
\text { - Tudo é feito online. } \\
\text { - O processo de projeto, as interferências e os } \\
\text { resultados são compartilhados por todos os } \\
\text { envolvidos, todo o processo é totalmente aberto. } \\
\text { - É uma colaboração competitiva e uma competição } \\
\text { colaborativa ao mesmo tempo. } \\
\text { - São } 337 \text { designers cadastrados. E não tem nenhum } \\
\text { critério de seleção, qualquer pessoa pode contribuir } \\
\text { com as propostas de projeto. }\end{array}$ & $\begin{array}{l}\text { - Os profissionais são contratados de acordo com a } \\
\text { demanda de projeto. O banco de dados tem } 250 \\
\text { profissionais já selecionados, todos com graduação ou pós- } \\
\text { graduação. } \\
\text { - Os líderes de projetos são pessoas oriundas da empresa. } \\
\text { - Os projetos são criados em conjunto, compartilhando e } \\
\text { construindo a partir da ideia do outro. } \\
\text { - Desenvolve projetos colaborativos envolvendo pessoas } \\
\text { da empresa e profissionais externos. } \\
\text { - Divulgar essa ideia de design mais estratégico e design } \\
\text { mais conceitual. }\end{array}$ \\
\hline
\end{tabular}

Quadro 2 - Características das plataformas. 
De acordo com os objetivos propostos, destacam-se algumas discussões relevantes que foram observadas no decorrer da análise das pesquisas realizadas junto às plataformas de design, dentre elas: conceito de plataforma; domínio e abrangência; dinâmica de interação existente nas plataformas; formas de relação e interação; plataformas de design; liberdade criativa.

Ao analisar as pesquisas realizadas no Projeto Maestro e Invalley observou-se que as duas plataformas apresentam diferentes conceitos de plataforma. O Projeto Maestro é uma plataforma de livre contato entre empresas e designers, mediada pelo articulador e suportada pelas novas tecnologias. Oferece design de comunicação para clientes que não têm acesso a este serviço em função de preço e região geográfica de localização. Proporciona uma primeira experiência de design para empresas que, até então, não investiram em design. Seu público são MPE's que começam a se interessar por design. Para esses, o Projeto Maestro oferece os serviços de uma rede de profissionais cadastrados na plataforma. O ambiente de comunicação entre os atores (articulador, empresário e designer) é a rede de internet, tudo é feito online. E o conceito que move o negócio desenvolvido pelo Projeto Maestro é um conceito aplicado à articulação de plataformas de design, pois uma plataforma é um ambiente de interação e reutilização projetado para atingir um domínio de aplicação (ALTIZER, 2002).

Já a Invalley é uma empresa que, através das informações contidas no site, declaradamente se propõe a conectar profissionais, empresas e investidores de forma presencial. No decorrer das entrevistas, observou-se que a Invalley opera de forma semelhante a um escritório de design: conexão entre profissionais, empresas e investidores, de fato, não ocorre por meio de uma plataforma aberta, mas ao longo do desenvolvimento de seus processos projetuais, que são fortemente liderados pelos sócios. Esses processos são caracterizados por workshops colaborativos, em que os funcionários da empresa cliente e profissionais externos são convidados a participar para compartilhar ideias e desenvolver produtos. Dessa forma, os processos são enriquecidos pelo olhar interdisciplinar e interfuncional dos participantes.

Com relação ao domínio e abrangência, as plataformas pesquisadas desfrutam de relações locais, regionais, estaduais e nacionais. Ambos os casos estudados oportunizam a inserção de designers nas empresas situadas nas grandes cidades, bem como nas cidades menores e do interior (onde a concentração de profissionais da área é menor). Através dessa inserção, é possível desenvolver pequenas inovações nos seus processos, produtos e serviços, por meio do design.

Conforme observado nas relações e interações realizadas pelos casos pesquisados, o mundo digital favorece negociações diretas para a prestação de serviços para empresas, qualquer que seja seu tamanho e o tipo de serviço ou produto que elas oferecem. Castells (2006) lembra que esse é um fato irreversível, que marcará indelevelmente as relações comerciais desde o início de século e será drasticamente acentuado nas próximas décadas em todo o mundo e em qualquer atividade, sem exceções.

Os dois casos analisados evidenciam como as plataformas procuram o desenvolvimento de múltiplas interações para além da relação entre designer e clientes e 
delineia algumas dinâmicas de interação identificadas nas plataformas, através das pesquisas.

A Invalley não proporciona dinâmicas de interação pela plataforma, apenas ao longo do processo de projeto. Com isso, observa-se que as dinâmicas de interação são presenciais e similares às dinâmicas de interação dos processos de projetos das agências de consultoria em design e inovação.

Já no Projeto Maestro, a interação é feita através da rede em que o articulador distribui e compartilha essas informações com empresários e designers. Observou-se que este apresenta dois tipos de dinâmicas de interação: a dinâmica de concorrência entre os diversos atores e a dinâmica de feedbacks do articulador, do empresário e do designer, ou seja, abrir totalmente as informações projetuais.

Observou-se, também, que existe uma interação no decorrer do processo de projeto e existe um processo cooperativo de maneira distinta em ambas as plataformas.

A evolução da web possibilitou a criação de espaços cada vez mais interativos, através de redes de interação aberta que proporcionam uma inovação aberta. Com base em Neumeier (2010) e Chesbrough (2010) a inovação aberta refere-se a um fluxo aberto, que utiliza a inteligência coletiva para incorporar novos conhecimentos na empresa.

Quem perceber as mudanças e souber usufruir das tecnologias para a criação de espaços interativos, criará um diferencial competitivo e novas oportunidades de mercado. E é isso que as plataformas pesquisadas têm como propósito, cada uma com seu nicho de mercado: a Invalley através da metodologia do design thinking ajuda as organizações a gerarem competitividade, desenvolvendo projetos de inovação através do design e o Projeto Maestro oferece design de comunicação com qualidade para clientes que não tinham acesso a este, em função do preço e da localização geográfica.

Dessa forma, observa-se que o design se estrutura de diferentes formas em cada plataforma e, embora os conceitos dessa área ainda sejam trabalhados de forma incipiente, é dada importância ao design como forma de relação e interação entre os atores para inovar.

As MPE's podem usufruir das plataformas de design para a inserção de design às empresas que ainda não têm design, pois as plataformas eliminam as distâncias geográficas entre profissionais e MPE's. Esta é uma das formas de relação das plataformas pesquisadas. Para os empresários entrevistados, a rapidez de resposta que o trabalho realizado pelas plataformas proporciona, permite afirmar que essa é uma das vantagens desse tipo de serviço bem como a quantidade de propostas que são apresentadas em um curto espaço de tempo.

A redução de custos dos processos, produtos e serviços oferecidos pelas plataformas de design é outra forma de relação e interação.

O fomento do design também pode ser considerado outra forma de relação e interação, pois as plataformas pesquisadas têm dois desafios: instigar o design nesses empresários e fazer com que eles verifiquem que o design pode dar retorno financeiro para a empresa em questão. E os articuladores das plataformas têm o desafio de estimular e desenvolver essa nova modalidade de negócio que pode ter uma grande 
demanda no mercado futuro. Ou seja, deverá mostrar resultados nos dois sentidos: num novo modelo de organização e tentar introduzir o design nessas empresas, nesses locais em que ainda não existe.

Com relação às formas de cooperação a consolidação de redes é abordada por Balestrin e Verschoore (2008) como meio dinâmico de integrar competitivamente. Através das respostas apresentadas nas pesquisas, constata-se que ambas as plataformas de design estudadas não operam em redes de cooperação interorganizacionais, pois não preconizam objetivos comuns claramente definidos.

Partiu-se do princípio que as plataformas estudadas eram plataformas de cooperação, mas, estudando os casos, no decorrer da pesquisa, percebeu-se que essas plataformas não são tão cooperativas e que também está presente a competição.

Essa competição também pode influenciar na liberdade criativa. No processo tradicional, o designer e o escritório se encontram reféns de um briefing e do relacionamento direto com a empresa e, quando o designer participa de um projeto intermediado por uma plataforma de design, em que existe uma concorrência com outros designers, em que participam diversos profissionais, em que existe uma competição entre designers, observa-se que o designer sente mais liberdade para expressar suas ideias. 


\section{CONCLUSÃO}

O tema proposto para esta pesquisa investigou a realidade atual de plataformas de design e sua importância para alavancar desenvolvimentos e pequenas inovações em MPE's. O estudo de caso realizado nas plataformas Projeto Maestro e Invalley Inovação e Design permitiu que fosse compreendida a forma de desenvolvimento e de funcionamento dessas plataformas, bem como os processos de relação e interação entre articulador, designers e empresários.

A partir dos estudos realizados foi possível obter a (re)conceituação de plataformas de design. As plataformas de design são contextos de trabalho que veiculam o fluxo de informação próprio de um processo de projeto, permitindo e favorecendo a relação e a interação presencial e remota entre os designers e os atores das empresas. Dessa forma, permitem às empresas praticar processos de projetos com custos menores, prazos reduzidos e agilidade.

Também, constatou-se que o conceito de plataforma de design não demanda uma estrutura física própria. O processo de projeto pode ocorrer totalmente online (como no caso do Projeto Maestro) ou nas estruturas das mesmas empresas (como em alguns projetos do caso Invalley Inovação e Design).

Outra contribuição evidenciada no decorrer do estudo é a importância das relações e interações desenvolvidas entre os atores. E essa relação em rede possibilita a interação projetual e a abertura do processo projetual. Com a abertura do processo projetual, as vantagens não são mais uma forma colaborativa de relacionamento, mas sim, a possibilidade de acessar ao design, pelos designers e pelas empresas e compartilhar conhecimentos a respeito do design.

A partir do momento que a plataforma disponibiliza as informações de projeto em uma rede aberta, ela se torna uma plataforma de cooperação: essa interação efetivamente se configura como uma espécie de cooperação na interação entre designers, empresários e articuladores.

Portanto, constata-se que no decorrer do processo de projeto a cooperação se mistura com a competição, resultando assim em uma coopetição. $E$, de maneira distinta e em maior ou menor proporção, essa coopetição é observada em ambas as plataformas pesquisadas. Porém, (re)conceituar as plataformas de design com base nas relações e interações, implica em formas cooperativas, colaborativas e também, competitivas.

Constata-se que em ambas as plataformas pesquisadas existem dois tipos de competição: a competição para ganhar o cliente e a competição criativa entre os designers para mostrar quem é o mais capaz projetualmente, para se sobrepor perante os outros profissionais, ou seja, é mais um desafio entre os designers. E essa competição criativa pode proporcionar visibilidade do trabalho desses profissionais perante o mercado, pois os designers têm a liberdade de mostrar o trabalho sem nenhuma interferência.

As plataformas de design surgem como alternativa eficaz para prestar serviços de design e essas plataformas assumem um papel de fomento do design, pois promovem o design nas empresas, facilitam a inserção do design nas empresas, inclusive 
favorecendo a inserção de jovens designers.

Assim, compreendeu-se que um dos grandes desafios para a consolidação das plataformas de design no mercado local, regional, nacional ou internacional reside em promover a inserção do design e inovações para MPE's gerarem um diferencial competitivo. As plataformas de design são uma nova modalidade de negócio que está surgindo e está sendo desenvolvida e perpetuada pelo Brasil. Por isso, sugerem-se novas pesquisas para que essa modalidade de negócio seja estudada mais detalhadamente, principalmente, no contexto voltado ao território e às redes de relações interorganizacionais e suas variadas formas de organização, bem como compreender quais estratégias podem ser desenvolvidas por meio do instrumento plataformas de design.

\section{REFERÊNCIAS BIBLIOGRÁFICAS}

ALTIZER, B. Platform-Based Design: the next reuse frontier. In: Embedded Systems Conference San Francisco. Mar 2002.

AMATO NETO, J. Redes de cooperação produtiva e clusters regionais: oportunidade para as pequenas e médias empresas. Atlas: São Paulo, 2000.

ARQUILLA, V.; GENCO, D. Changing the change: DAC_Link A 2.0 tool for SME's design innovation. In: Umberto Allemandi \& C, - Torino, July 2008.

BALESTRIN, A.; VARGAS, L. M. A dimensão estratégica das redes horizontais de PMEs: teorizações e evidências. RAC: Edição Especial, p. 203-227, 2004.

BALESTRIN, A.; VERSCHOORE, J. Redes de cooperação empresarial: estratégias de gestão na nova economia. Bookman: Porto Alegre, 2008.

BERENDS, H.; REYMEN, I.; STULTIËNS, R. G. L.; PEUTZ, M. External designers in product design processes of small manufacturing firms. Design Studies, 32 (2011), 86$108,2011$.

BRAGA, M. M. Uma proposta de modelo de plataforma de colaboração para comunidade de prática no ambiente de TV digital. Tese de Doutorado e Engenharia e Gestão do Conhecimento: Universidade Federal de Santa Catarina, 2012.

CASTELLS, M. A sociedade em rede. 6 ed. São Paulo: Paz e Terra, 2006.

CHESBROUGH, H. Modelos de negócios abertos: como prosperar no novo cenário da inovação. Bookman: Porto Alegre, 2012.

GOLDMAN, S.; NAGEL, R.; PREISS, K. Agile competitors: concorrência e organizações 
virtuais. Érica: São Paulo, 1995.

LASTRES, H. M. M.; PIMENTEL, G. Design em arranjos e sistemas de MPME: proposição de políticas para a promoção de sistemas produtivos locais de micro, pequenas e médias empresas. Universidade Federal do Rio de Janeiro, 2001.

MERONI, A. Strategic Design: where are we now? Reflection around the foundations of a recent discipline. Strategic Design Research Journal, 1 (1): 31-38, Jul-Dez, 2008.

MERRICK, K; GU, N; WANG, X. Case studies using multiuser virtual worlds as an innovative platform for collaborative design, ITcon, Vol. 16, p. 165-188, 2011.

NEUMEIER, M. A empresa orientada pelo design. Bookman: Porto Alegre, 2010.

SANGIOVANNI-VINCENTELLI, Alberto. Defining Platformbased Design. EE Design of EE Times, february, 2002.

SILVA, C. B. O design como estratégia de diferenciação para micro e pequenas empresas: o caso da indústria moveleira em dois municípios do estado do Amazonas. Dissertação de Mestrado em Engenharia de Produção: Universidade Federal de Santa Catarina, 2004.

TEIXEIRA, J. A. O design estratégico na melhoria da competitividade das empresas. Tese de Doutorado em Engenharia de Produção: Universidade Federal de Santa Catarina, 2005.

YIN, R. K. Estudo de Caso: planejamento e métodos 4 ed., Bookman: Porto Alegre, 2010.

ZURLO, F. Design Strategico. In: AA. VV., Gli spazi e le arti, Vol. IV, Opera XXI Secolo, Editore Enciclopedia Treccani, Roma, 2010. 